Mini Review

\title{
Application of infrared thermography in the assessment of muscle damage in elite soccer athletes
}

\begin{abstract}
The participation in a soccer match may result in a large number of micro-injuries leading to a number of physiological responses which, in turn, increase skin temperature $\left(T_{\mathrm{sk}}\right)$ of the lower limbs. The measurement of $T_{\text {sk }}$ using infrared thermography (IRT) is being used as a tool to evaluate the internal load of the athlete in order to assist the management of training load and to help in the prevention of muscle injuries.
\end{abstract}

Keywords: Infrared thermography, Muscle damage, Skin temperature, Soccer athletes
Volume 8 Issue 5 - 2017

\author{
Alex de rade Fernandes,' Eduardo \\ Mendonça Pimenta, ${ }^{2}$ Danilo Gomes \\ Moreira,' João Carlos Bouzas Marins, ${ }^{3}$ \\ Emerson Silami Garcia ${ }^{4}$ \\ 'Department of Physical Education, Federal Institute for \\ Education, Science and Technology of Minas Gerais, Brazil \\ ${ }^{2}$ Department of Physical Education, Physiotherapy, and \\ Occupational Therapy School, Federal University of Minas \\ Gerais, Brazil \\ ${ }^{3}$ Department of Physical Education, Federal University of Vi?osa, \\ Brazil \\ ${ }^{4}$ Senior Visiting Researcher, Department of Physical Education, \\ Federal University of Maranhao and CAPES/FAPEMA, Brazil
}

\author{
Correspondence: Alex de Andrade Fernandes, Federal \\ Institute for Education, Sciences and Technology of Minas Gerais, \\ Av. Joao Valentim Pascoal, s/n - Centro - Ipatinga - Minas Gerais, \\ Brazil,Tel 55-3|-3899-2076, Fax 55-3I-3899-2076 \\ Email alex.andrade@ifmg.edu.br
}

Received: July 15, 2017| Published: August 08, 2017

\section{Abbreviations \\ $T_{\text {sk }}$, Skin Temperature; IRT, Infrared Thermography \\ Introduction}

Participation in a soccer match results in a large number of microinjuries originated by the eccentric mechanical actions, generating muscle fiber ruptures, cell membrane damage, and sarcomere degeneration. ${ }^{1}$ Following this process, an acute local inflammatory response is triggered involving the release of different cytokines, migration of neutrophils to the trauma areas, and the release of certain agents into the damaged fibers to attract macrophages that ingest and digest the dead tissue, promoting temperature increase. ${ }^{2}$ In this sense, studies have demonstrated a significant increase in tsk assessed through IRT after physical effort, which could be an indicator of muscular wear, evidencing the athlete's physical exhaustion. ${ }^{2,3}$

\section{Discussion}

The acute inflammatory response presented after soccer matches results in the appearance of some cardinal signals produced by the organism such as: heat, redness, pain and swelling. ${ }^{4}$ The redirection of arterial blood flow to the exercised muscle generates a higher muscle temperature and a greater local cutaneous vasodilation. This process is followed by a sensation of perceived heat, as well as the redness due to the greater number of erythrocytes that transited in the affected area. ${ }^{4}$ In addition, during the inflammatory process, the blood flow velocity is reduced, which allows the interaction of circulating cells with endothelial cells expressing surface molecules capable of binding to leukocytes. ${ }^{5}$ It is also important to note that during exercise and post-exercise there is a release of proinflammatory cytokines TNF- $\alpha$,
IL-1 $\beta$ and IL-6 that can remain elevated for a period of 24-48 hours. ${ }^{6}$ and concomitantly act as endogenous pyrogens, thus contributing to the increase of the internal temperature. ${ }^{5}$

Considering the factors that trigger the inflammatory process, which consequently alter the skin temperature, it has been proposed the assessment of skin temperature through IRT as an indirect way of measuring muscle damage caused by different types of exercise, especially those with eccentric characteristics. Therefore, the use of IRT can be used as a noninvasive way of measuring body's responses (heat) to the inflammatory process, and can provide valuable information about how the external load was assimilated by the athlete. Therefore, it would be important to study the potential of this strategy for controlling the training load of high performance athletes. ${ }^{7}$

It is important to emphasize that muscular and cutaneous vasodilatation lead to increased blood flow in the exercised limb. However this is not the only reason for the increase in $T_{\text {sk }}$. In fact, the highest blood supply during exercise, with arterial blood at a higher temperature in muscle and skin, is the main factor that promotes the increase of $T_{\mathrm{sk}}$. For example, in resting conditions, the expected blood temperature range is $36.8-37.9^{\circ} \mathrm{C}^{8}$ and consequently the displacement of this blood flow at a higher temperature in exercised subjects will result in a higher muscle and skin temperatures. ${ }^{9}$

Fernandes et al. ${ }^{2}$ studied the $T_{\text {sk }}$ changes after a professional football match of the Brazilian championship of the First National Division. The $T_{\text {sk }} 24$ hours after the game ranged from $2.0^{\circ} \mathrm{C}$ to $2.5^{\circ} \mathrm{C}$ higher in the posterior area of the thighs than before the game. However, no evidence of injury was identified by the medical staff. Therefore, the authors concluded that the increase of $T_{\mathrm{sk}}$ after the match could be attributed to the inflammatory process, since the results of creatine 
kinase tests were also elevated $24 \mathrm{~h}$ after the game. Figures $1 \& 2$ present the thermal images recorded at the different moments in anterior and posterior views respectively.

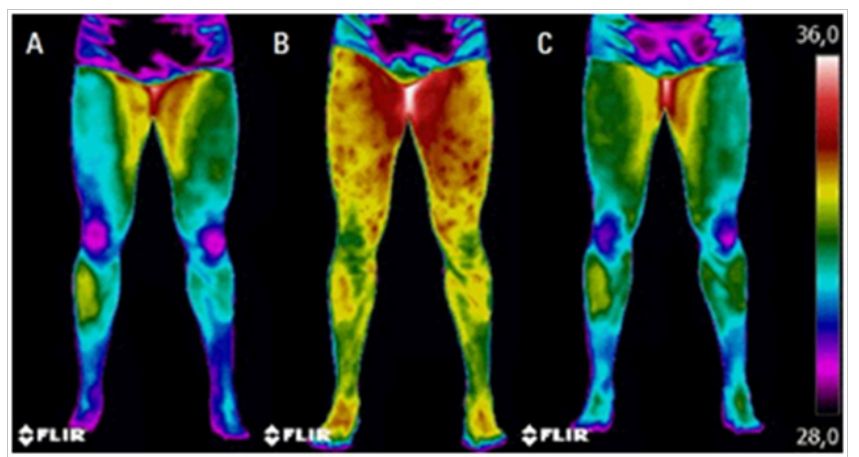

Figure I Thermograms of the anterior views: (A) $24 \mathrm{hr}$ before the match, (B) $24 \mathrm{hr}$ after starting the match, and (C) $48 \mathrm{hr}$ after starting the match. ${ }^{2}$

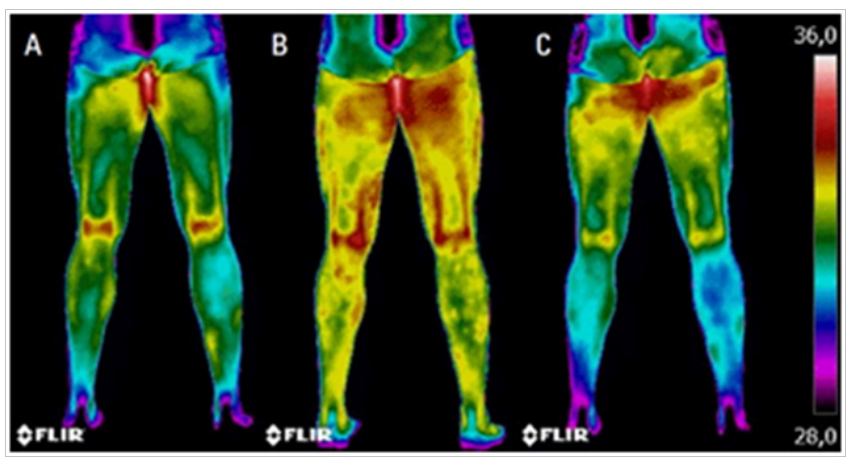

Figure 2 Thermograms of the posterior views: (A) $24 \mathrm{hr}$ before the match, (B) $24 \mathrm{hr}$ after starting the match, and (C) $48 \mathrm{hr}$ after starting the match. ${ }^{2}$

One of the advantages of using IRT to measure $T_{\mathrm{sk}}$ is the relative low cost of some infra-red camera models. Since it is a non-invasive technique, $T_{\mathrm{sk}}$ monitoring can be performed focusing on a particular body region of interest (local analysis) as well as a broad view of the whole body, enabling a global analysis. ${ }^{10,11}$

\section{Conclusion}

The use of IRT may be a noninvasive alternative to measure $T_{\text {sk }}$, which can be applied as an indirect measure of the inflammatory process due to muscle damage, and being used as a tool to evaluate the internal load of the athlete in order to assist the management of training load and to help in the prevention of muscle injuries.

\section{Acknowledgements}

The authors of this article are indebted to the following research funding agencies: Federal Institute for Education, Science and Technology of Minas Gerais (IFMG); Coordination for the Improvement of Higher Education Personnel (CAPES); Foundation for Research Support of the Minas Gerais State (FAPEMIG); National Council of Scientific and Technological Development (CNPq).

\section{Conflicts of Interest}

No potential conflict of interest relevant to this article was reported.

\section{References}

1. Hyldahl RD, Hubal MJ Lengthening our perspective: morphological, cellular, and molecular responses to eccentric exercise. Muscle Nerve. 2014;49(2):155-170.

2. Andrade Fernandes A, Pimenta EM, Moreira DG et al. Effect of a professional soccer match in skin temperature of the lower limbs: a case study. J Exerc Rehabil. 2017;13(3):330-334.

3. Al-Nakhli HH, Petrofsky JS, Laymon MS et al. The use of thermal infra-red imaging to detect delayed onset muscle soreness. $J$ Vis Exp. 2012;(59):e3551.

4. Punchard NA, Whelan CJ, Adcock I The journal of inflammation. Journal of Inflammation. 2004;1(1):1.

5. Fehrenbach E, Schneider ME Trauma-induced systemic inflammatory response versus exercise-induced immunomodulatory effects. Sports Med. 2006;36(5):373-384.

6. Mohr M, Draganidis D, Chatzinikolaou A et al. Muscle damage, inflammatory, immune and performance responses to three football games in 1 week in competitive male players. Eur J Appl Physiol. 2015;116(1):179-193.

7. Marins J, Fernández-Cuevas I, Arnaiz Lastras J et al. Applications of Infrared Thermography in sports. A review. International Journal of Medicine and Science of Physical Activity and Sport. 2013;15(60):805-824.

8. Davie A, Amoore J 2010 Best practice in the measurement of body temperature. Nursing Standard. 2013;24(42):42-49.

9. Bhargava A, Chanmugam A, Herman C Heat transfer model for deep tissue injury: a step towards an early thermographic diagnostic capability. Diagnostic Pathology. 2014;9(1):36.

10. Fernandes AA, Amorim PRS, Brito CJ et al. Measuring skin temperature before, during and after exercise: a comparison of thermocouples and infrared thermography. Physiol Meas. 2014;35(2):189.

11. Marins JCB, Fernandes AA, Moreira DG et al. Thermographic profile of soccer players' lower limb. Rev Andaluza Med Dep. 2014;7(1):1-6. 